\title{
Design proposal for door thresholds
}

\author{
Radim Smolka ${ }^{1, *}$, Jindřich Sobotka ${ }^{1}$, and Jindřiška Šulistová ${ }^{2}$ \\ ${ }^{1}$ Brno University of Technology, Faculty of Civil Engineering, \\ Institute of Building Structures, Veveří 95, 60200 Brno, Czech Republic \\ ${ }^{2}$ Institute of Technology and Business in České Budějovice, Czech Republic
}

\begin{abstract}
Panels for openings in structures have always been an essential and integral part of buildings. Their importance in terms of a building's functionality was not recognised. However, the general view on this issue has changed from focusing on big planar segments and critical details to sub-elements of these structures. This does not only focus on the forms of connecting joints but also on the supporting systems that keep the panels in the right position and ensure they function properly. One of the most strained segments is the threshold structure, especially the entrance door threshold structure. It is the part where substantial defects in construction occur in terms of waterproofing, as well as in the static, thermal and technical functions thereof. In conventional buildings, this problem is solved by pulling the floor structure under the entrance door structure and subsequently covering it with waterproofing material. This system cannot work effectively over the long term so local defects occur. A proposal is put forward to solve this problem by installing a sub-threshold door coupler made of composite materials. The coupler is designed so that its variability complies with the required parameters for most door structures on the European market.
\end{abstract}

\section{Introduction}

Financial incentives, Czech standards and European Union directives is motivating builders to build low-energy and passive houses. As a result, the material characteristics of the products used has improved and continues to do so. At the same time, new construction technologies are being put into practice, and ever increasing demands placed on the economical, technical-physical, technological, hygiene, fire prevention, environmental and aesthetics of buildings. Unfortunately, there are numerous limiting factors which have revealed design and consequently implementation faults in low-energy or passive houses. The biggest issue is the occurrence of thermal bridges and the quality of the implementation of critical details. The lack of prevention of the occurrence of thermal bridges is a frequent problem in the construction of low-energy and passive buildings, particularly in more complicated structure details, which are slightly suppressed in conventional constructions. The requirements for the quality of the design and implementation of a building are therefore increasing, which has a simultaneous impact on costs.

\footnotetext{
* Corresponding author: smolka.r@fce.vutbr.cz
} 
The demand for disposable packaging is increasing rapidly in the world, with consumption approaching two million tonnes a year in the Czech Republic. Development in this field are closely linked to the use of composite materials including those based on recycled plastics. In the Czech Republic, the quantity of packaging that needs to be recycled is also growing rapidly. Public education and the location of special bins in densely populated areas has contributed to this. Nevertheless, tens of thousands of secondary plastic raw materials, including plastic bottles, end up at domestic waste landfill sites. A polymer becomes a plastic after being mixed and combined with the necessary additives and transformed into a form suitable for further technological processing e.g. grains, powder, tablets, etc. The term "polymer" is understood to mean a chemical substance, whilst "plastic" is a technical material with specific usable properties.

\section{Processing method}

When choosing the areas for research, consideration was given to the construction details of low-energy and passive constructions. Particular attention was focused on the carcass of a building, which is critical in terms of both design and implementation. As a result, the design of the bottom of a door structure, the plinth of an aired facade and the base area of a roof structure were selected. The most important requirements placed on structure elements are: thermal insulation, airtightness, vapour-tightness, waterproofing, fire resistance, strength and stability, soundproofing, health and safety.

\section{Improvement of polymer properties}

To improve the polymer properties of products used in construction, antidegradants are added. These additives protect the products on a long-term basis against external influences such as sunlight, atmospheric oxygen, ozone and thermal energy.

Antidegradants can be divided into three categories:

- light stabilizers - absorb UF radiation,

- antioxidants - eliminate oxidation (aging),

- antiozonants - eliminate the influence of ozone.

Other additives that influence the properties of polymeric substances include:

- fillers,

- hardeners - substance strengthening,

- blowing agents - expanded substances,

- pigments - colours of mixtures,

- optically lightening substances - absorption of UV light,

- antistatic additives,

- factices - improvement of surface smoothness,

- adhesive agents,

- agents which decrease combustibility - retarders, extinguishers [1].

These most frequently used additives are normally used in secondary materials - fence blocks, grass blocks, step blocks [2]. 


\section{Structure element of sub-threshold door couplers}

The structure details of door panes in constructions have to be determined on the basis of their thermal, mechanical and chemical properties, but also from the point of view of the user. In so doing, it is necessary to eliminate the heat flow below the door frame structure and to connect and terminate the waterproofing and thermal insulation elements.

\subsection{Secondary plastic material}

This section specifies the secondary plastic raw materials that were assessed and tested.

\subsubsection{Selected raw materials and their characteristics}

The thermal conductivity coefficient is affected by the basic properties of the individual polymers and by the proportion of additives used to create the plastic material. The value of the thermal conductivity coefficient is reduced by the removal of the plastic filling and the addition of other additives and components (application of a blowing agent, granulate soaking, etc.), as well as by the technology (moulding, injection) used for the production thereof.

Table 1. Measured thermal conductivity coefficient $\lambda\left[\mathrm{W} \mathrm{m}^{-1} \mathrm{~K}^{-1}\right]$ values.

\begin{tabular}{|c|c|c|c|c|}
\hline Designation & Material & Acronym & Characteristic & $\lambda\left[\mathbf{W ~ m}^{-1} \mathbf{K}^{-1}\right]$ \\
\hline 1. D) & polyamide & PA & & 0.196 \\
\hline 2. D) & polycarbonate & PC & & 0.236 \\
\hline 3. D. a) & \multirow{2}{*}{ polystyrene } & PS & tough & 0.345 (max. value) \\
\cline { 4 - 5 } 3. D. b) & \multirow{2}{*}{ polyvinylchloride } & PS & brittle & - \\
\cline { 1 - 3 } 4. D. a) & PVC & clear & 0.287 \\
\hline 4. D. b) & PVC & white & 0.315 \\
\hline 5. D) & high-density polyethylene & HDPE & black & 0.125 \\
\hline 1. A) & A1005 & & & 0.103 (min. value) \\
\hline 2. A) & A1006 & & & 0.152 \\
\hline 3. A) & A1007 & & & 0.148 \\
\hline 1. S) & $\begin{array}{c}\text { amorphous blends of } \\
\text { styrene acrylonitrile }\end{array}$ & ABS & red & - \\
\hline 2. S) & amorphous resin & ASA & grey & - \\
\hline 3. S) & $\begin{array}{c}\text { Amorphous polycarbonate } \\
\text { polymer }\end{array}$ & PC & clear & 0.262 \\
\hline 4. S) & polyamide 6 & PA 6 & brown & 0.165 \\
\hline \multirow{2nnnyy}{*}{ 5. S) } & $\begin{array}{c}\text { semi-crystalline } \\
\text { polyethylene terephthalate }\end{array}$ & PBT & white & 0.187 \\
\hline 6. S) & amorphous polyetherimide & PEI & brown & - \\
\hline 7. S) & thermoplastic polymers & TPU & mixture & 0.152 \\
\hline
\end{tabular}

The results in Table 1 show worse thermal conductivity coefficient parameters compared to the insulation material used today. In terms of the thermal conductivity coefficient the above samples are between three to nine times worse than the thermal insulation normally used [3-5]. 


\subsubsection{Theoretical design of a product for construction}

The requirements for products to be used in the construction industry for the elimination of thermal bridges are given. These requirements should be applicable to both new buildings (passive and low-energy constructions) and to existing buildings undergoing reconstruction or modification.

For the purposes of this study structure details for new constructions, particularly for low-energy and passive constructions, have been selected. This selection includes details of corners, horizontal structures, filling of construction structures, masonry footings and the filling of structure openings. The most common threshold arrangement for entrance doors are: aluminium threshold profile with interrupted thermal bridge; barrier-free solution with additional sealing with a movable seal in a special profile embedded in the floor structure.

The proposed sub-threshold door coupler should replace existing substructures in the floor structure. The substructure should consist of at least two boards of recycled plastic and should enable variable connection to the waterproofing structure [6]. To accommodate for varying designs in floor thicknesses and other local influences, the substructure must be a variable arrangement. For such a variable arrangement and for ease of installation, the shape of the substructure boards should be such that the boards fit into or onto each other. They should also be able to be easily cut to size to fit every structure detail (see Figure 1).

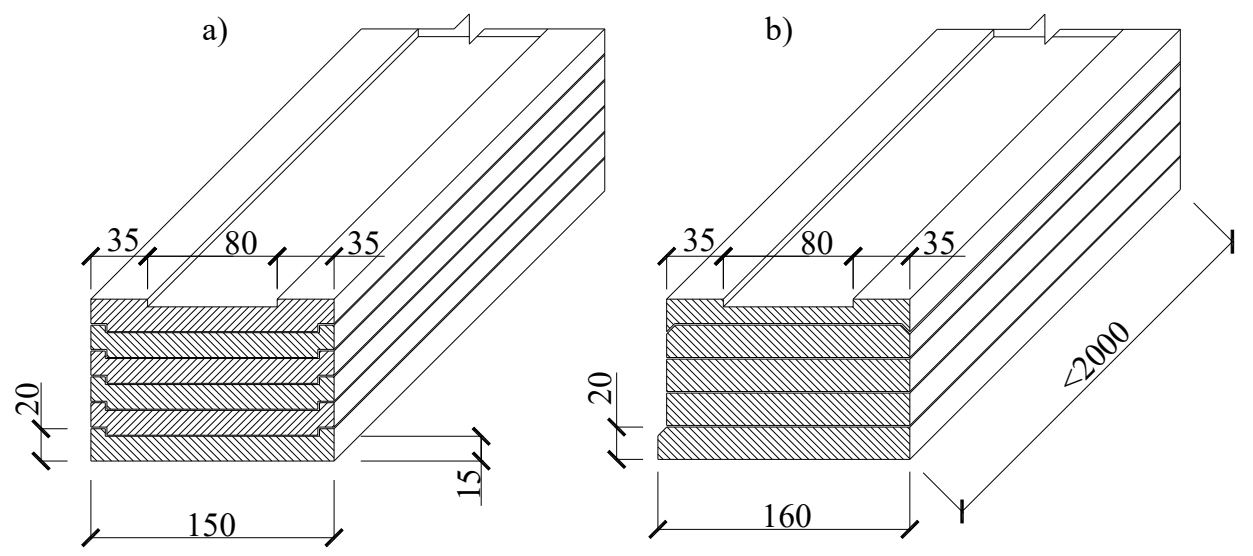

Figure 1. Alternative threshold coupling systems made of secondary raw materials - axonometric view.

The design of the boards and their material characteristics should ensure the distribution of the dynamic load, caused by normal operation, to the subbase layers. The board must also be non-water absorbing and diffusion proof [1, 7-9].

\subsubsection{Analysis and comparison of the thermal-technical properties of the structure after theoretical integration of the product}

This section illustrates the structure details of a proposed solution which incorporates the proposed product.

For the analysis, the thermal insulant which is normally used in practice is substituted by the proposed sub-threshold door coupler. The door coupler is made of secondary plastic raw materials with a thermal conductivity coefficient of $\lambda=0.103\left[\mathrm{Wm}^{-1} \mathrm{~K}^{-1}\right]$ (the value was taken as the minimum of the measured values). 
The thermal-technical behaviour of the recycled plastic insulation block was modelled by means of the ANSYS computing system. For the thermal-technical analysis, the recycled plastic product was embedded into a wall that meets the requirements for passive houses (see Figure 2).

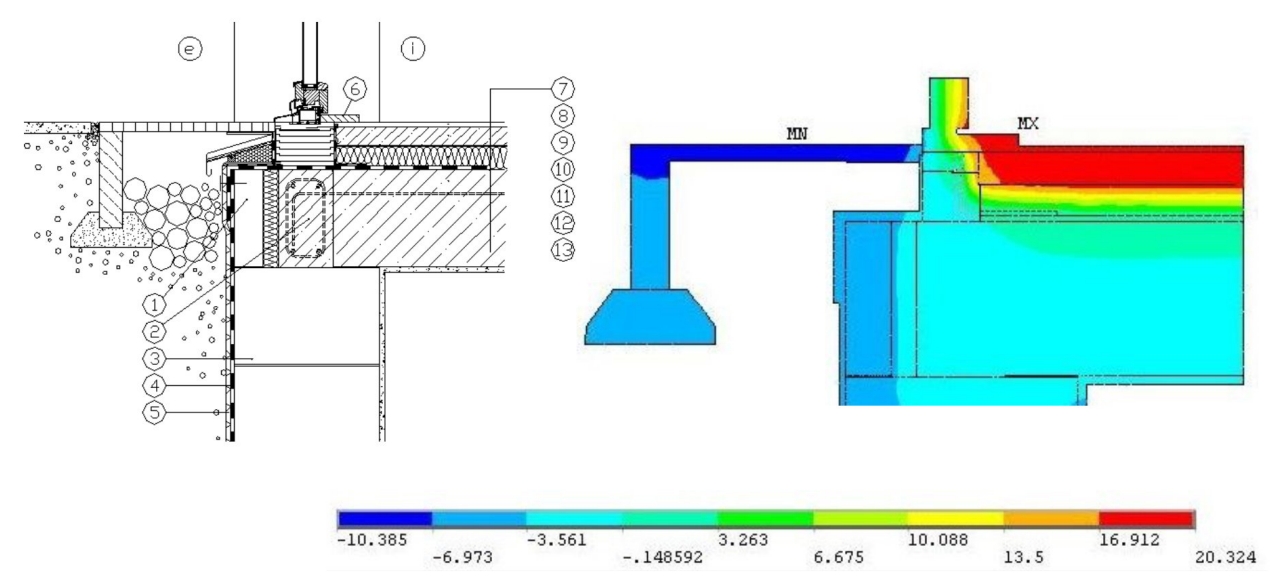

Figure 2. Structural detail of a threshold of a house with a cellar / temperature distribution.

It is clear from the selected and presented example that the sub-threshold door coupler has to be supported by additional thermal insulation. However, this does not have to be under the door structure but can be a part of the thermal insulation of the plinth or subterranean part of the building. Once the value of the thermal conductivity coefficient approximates that of standard thermal insulation (approx. $\lambda=0.035 \mathrm{~W} \mathrm{~m}^{-1} \mathrm{~K}^{-1}$ ), the subbase structure could be shifted to the exterior.

\section{Conclusion}

Materials derived from recycled plastic have great potential for use in a broader range of civil engineering applications. Their technical properties i.e. physical, mechanical and chemical, predispose them for use in structures where conventional thermal insulation is normally used. When using a product derived from secondary raw materials the structure thickness can be reduced. The reason for this is that it is no longer necessary to use other waterproofing or bearing layers because the requirements under technical standards, regulations and laws are all fulfilled at the same time. Another indisputable advantage is the reduction in financial costs during construction. Sub-threshold coupling is only one of the few ways to make use of secondary raw materials in civil engineering [10].

This paper has been worked out under the project No. LO1408 "AdMaS UP - Advanced Materials, Structures and Technologies", supported by Ministry of Education, Youth and Sports under the „National Sustainability Programme I".

\section{References}

1. M. Novotný, K. Šuhajda, J. Sobotka, Z. Jiroušek, AMR 1122, 65-69 (2015)

2. V. Duchacek, Polymers - production, properties, processing, applications (Institute of Chemical Technology in Prague, 2006) 
3. CSN 73 0540-2 Thermal protection of buildings - Part 2: Requirements (Czech office for standards, metrology and testing, Prague, 2011)

4. S.L. Simon, G.B. Mckenna, J. Reinf. Plast. Compos. 18, 559-571 (1999)

5. L.A. Rorrec-Gomez, R. Yanez-nieto, Thermochim. Acta 140, 139-144 (1989)

6. J. Plachý, Bitumen sheet joints under the influence of temperature and time in the composition of single-membrane roofs (Doctoral thesis, Brno University of Technology, Faculty of Civil Engineering, Brno 2005)

7. L. Matejka, R. Smolka, Brno University of Technology: Support structures for a doors threshold, EP 2159364 B1, (patent, Munchen, 2012)

8. J. Pencik, L. Matejka, P. Zitt, Brno University of Technology: Material deformation testing stand for the long- term monitoring of deformation characteristics under constant pressure, EP 2078948 (patent, Munchen, 2009)

9. T. Petř́ček, P. Kacálek, R. Smolka, AMR 1041, 71-74 (2014)

10. R. Smolka, T. Petricek, P. Kacalek, enviBUILD 2014 - Buildings and Environment (Brno, 2014) 